\title{
Hepatic Peliosis with Extra-Hepatic Manifestations
}

\author{
Asma Javed, Salma Gul \\ Department of Radiology, Shifa International Hospital Islamabad, Pakistan. \\ Correspondence to: Dr Asma Javaid, Email:dr.asmajdq@hotmail.com, ORCiD: 0000-0002-3361-2164
}

\begin{abstract}
Liver is a common house for benign and neoplastic etiologies as well as infection. Controversy lies in diagnosing these pathologies which without the help of imaging, labs or histopathology is not possible. Some highly vascular like hemangiomas, the biopsy becomes contraindicated due to high chances of bleeding and hemodynamic shock. In such scenarios, we rely on imaging to give diagnosis to clinicians and also provide a roadmap. Recently, we encountered a rare scenario of peliosis hepatis, with extra-hepatic manifestations. Our main aim through this rare case report is to highlight this rare entity amongst clinicians and radiologists, since it can easily mimic hepatocellular carcinoma and atypical hemangiomas. It was through our close analysis and detailed literature review that we came to close the diagnosis.
\end{abstract}

Keywords: Hepatocellular Carcinoma (HCC), Peliosis Hepatis (PH), Magnetic Resonance Imaging (MRI).

This is an Open Access article distributed under the terms of the Creative Commons Attribution Non-Commercial License (http:// creative commons. org/licenses/by-nc/4.0) which permits unrestricted non-commercial use, distribution, and reproduction in any medium, provided the original work is properly cited.

\section{INTRODUCTION}

Peliosis Hepatic (PH) is another touch-me-not vascular lesion, defined as a tumor-like condition of liver in which multiple blood-filled cavities are formed due to sinusoidal dilatation. The exact etiology is still unclear. A possible cause being the obstruction of hepatic outflow at the sinusoidal level, breakdown of the sinusoidal borders, dilatation of the central venous system of the liver or necrosis of liver resulting in cavity formation. Due to this, there is a close resemblance of peliosis hepatis with hepatic hemangiomas, while other mimickers include hepatocellular carcinoma (HCC), liver abscesses or metastasis.

In a case report of two patients performed by Dai YN et al, one of them presented with symptoms and the other patient remained asymptomatic. Use of drugs like anabolic steroids, diethylstilbestrol, corticosteroids, immunosuppressant, tamoxifen, androgen, thiopurine and oral contraceptives. ${ }^{3.7}$ Infections such as Bartonella henselae and even tuberculosis have shown association with $\mathrm{PH}^{8,9}$ There has been reported link of $\mathrm{PH}$ with $\mathrm{HCC}$ and other hematological malignancies. ${ }^{10}$ However, no evidence could support a direct relationship between the above factors and the development of $\mathrm{PH}$.

\section{CASE REPORT}

A 35 years male presented with abdominal pain, anemia, constipation, weight loss on and off, and known case of hepatitis $C$. No other laboratory workup was done since the patient presented acutely with complains of abdominal distension and pain for past 4-5 days. On examination, the abdomen was tender with massive hepatosplenomegaly. Ultrasound was performed only which showed diffusely scattered lesions in liver and spleen, raising suspicion for multifocal hepatocellular carcinoma and splenic abscesses.

Furthermore, contrast enhanced Triphasic computed tomography (CT) scan was advised for further characterization of multifocal hepatic lesions. There was hepatomegaly with multiple nodular lesions of variable sizes slightly hyperattenuating on plain phase, studded in liver. On arterial phase, interrupted peripheral nodular enhancement was noted. On portovenous phase, centripetal pattern of enhancement was noted. Characteristically, these lesions were noted in close vicinity of distal tributaries of portal vein, representing sinusoidal contrast accumulation. This was seen as retention of contrast on delayed phase with lesions appearing hyperattenuating in comparison to background hepatic parenchyma (Figure 1). These lesions suggested internal blood products. Extrahepatic involvement was noted in spleen (Figure 2), which was diffusely enlarged with lesions showing near-complete replacement of splenic parenchyma, more conspicuous on portovenous and delayed phases (Figure 2). Signs of portal hypertension with prominent portal vein, tortuous splenic vein and 
numerous upper abdominal collaterals were seen. There was also gross abdominopelvic ascites and omento-mesenteric congestion. No vascular thrombosis was seen. Another striking feature of extrahepatic involvement was of osseus lesion, which showed multiple lucent lesions in T9, T10, T11, S1 and S3 vertebral bodies. Multiple lucent lesions were also seen in bilateral acetabulum and femoral heads (Figure $2 \mathrm{~b}$ and $2 \mathrm{c}$ ). Few of these lesions showed peripheral hyperdensities. Premature degenerative changes were seen in bilateral hip joints, with reduced joint space marginal osteophytes and asymmetrical flattening of right femoral head, this was a suspected cause in our case. Provisional diagnosis of hepatic peliosis was established, with extra hepatic manifestations. Biopsy is contraindicated in such cases. Unfortunately, patient couldn't survive and expired few days just after the initial investigations.

On basis of characteristic enhancement pattern and anatomical location, diagnosis of hepatic peliosis was established. The need for histopathological confirmation was then neglected.

\section{DISCUSSION}

It is believed that this vascular disorder when in liver, is associated with use of several drugs, infections and chronic wasting, like in post-transplant patients. ${ }^{3-8}$ The use of drugs like anabolic steroids, diethylstilbestrol, corticosteroids, immunosuppressant, tamoxifen, androgen, thiopurine and oral contraceptives are highly associated with peliosis. ${ }^{3.7}$ The parenchymatous organs like bone marrow, liver, spleen, kidneys, lungs, lymph nodes are frequently involved by peliosis." Idiopathic thrombocytopenic purpura is also thought to be one of the causative factor.'

The clinical presentations are variable, from patient's being asymptomatic to acute abdominal pain, intraabdominal hemorrhage or liver failure. Our patient had similar set of presentation where he developed acute abdominal pain, distention and liver failure within 10-14 days. Prompt diagnosis can lead to urgent surgical intervention in case of intra-abdominal bleeding or even liver transplant in case of liver failure. In many cases, the patient's die even before the start of treatment, like in our case scenario. And some patient's after receiving the treatment could lead a rather asymptomatic life. ${ }^{13}$

In radiology, different imaging spectrum have been described on Ultrasonography (USG), CT and MRI as described in literature. On CT scan plain phase, these lesions are usually hyper-attenuating owing to the internal hemorrhagic component because of the cystic sinusoidal dilatation. The lesions become slightly hyperdense during the portovenous and delayed phases. In our case, liver was studded with multiple lesions mostly hyperdense on plain phase suggesting the internal blood filled cavities. The peripheral nodular enhancement on arterial phase resembled those of hemangiomas. However, there was retention of contrast on delayed phase, contradicting hepatic hemangiomas pattern. Even in HCC, there is washout of contrast on portovenous and delayed phase. In our case, there was no sign of rupture of hepatic peliosis, however the extra-hepatic manifestations involving spleen and bone marrow can be seen due to parenchymal involvement of peliosis. Differentials for such cases in liver would include hemangiomas, adenomas, hepatocellular carcinomas, hypervascular metastasis. Familiarity with the clinical features of peliosis hepatis would help radiologists establish early and correct diagnosis. Triphasic CT study would be better in diagnosing the peliosis at an early stagê.

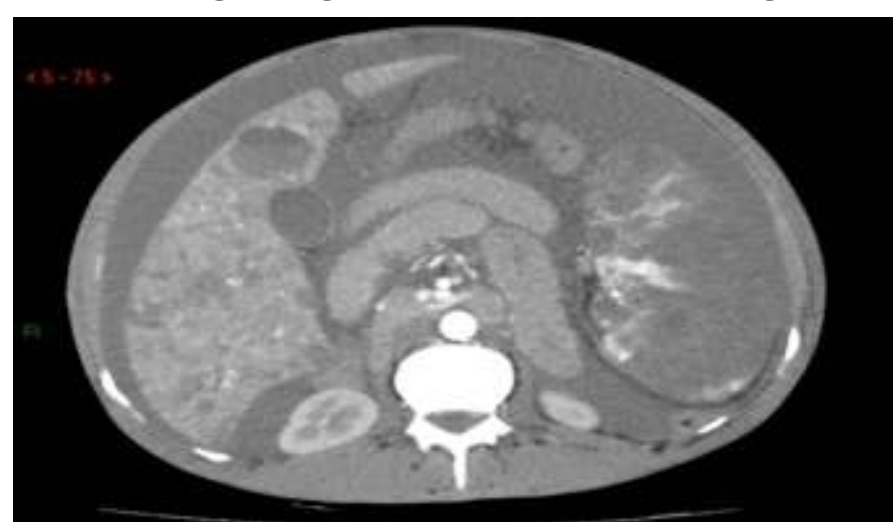

Figure $1 \mathrm{~A}$ : Arterial phase CECT of liver shows interrupted peripheral nodular enhancement was noted.

\section{CONCLUSION}

In our case report, patient had no underlying disease condition. The presentations were acute with sudden demise of patient due to the bleeding from the hepatic vascular lesions. Our purpose is to present the radiological presentation of hepatic peliosis which can be a strong mimicker of other vascular lesions like hemangiomas or HCC. If wrongly diagnosed, this can divert the clinician from proper initial investigation.

Biopsy is contraindicated in these touch-me-not vascular lesions, and hence help from radiological imaging should be carried out for establishing the diagnosis. Extra-hepatic manifestations are very unlike, like the disease itself, but once liver lesions are established, prompt attempt should be made to look for any other extra hepatic lesion. 

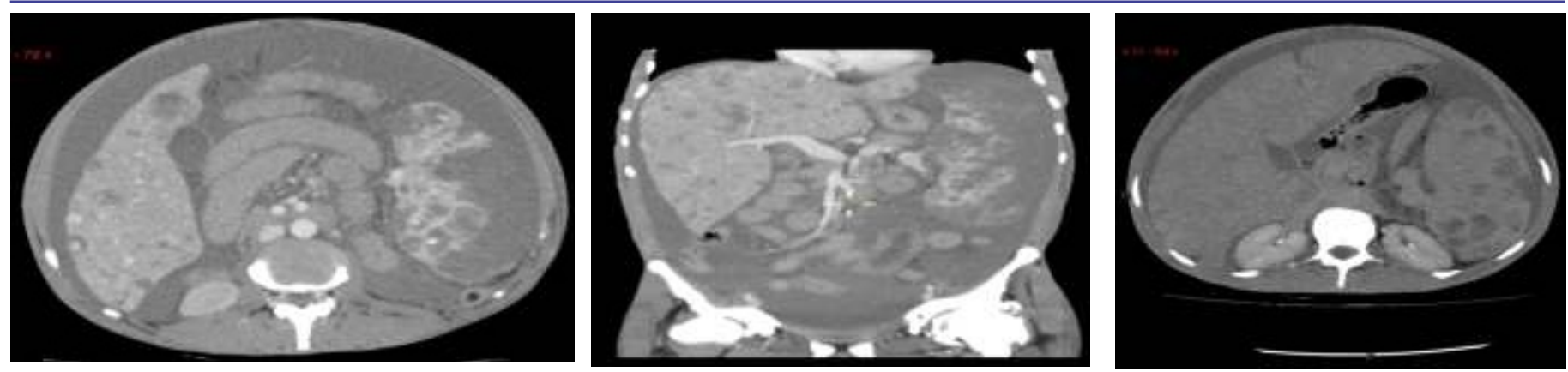

Figure $1 \mathrm{~B}$ axial, coronal and axial delayed images: On portovenous phase, centripetal pattern of enhancement was noted. Interestingly, retention of contrast was noted on delayed phase with lesions appearing hyperattenuating in comparison to bachground hepatic parenchyma. These lesions suggested internal blood products.

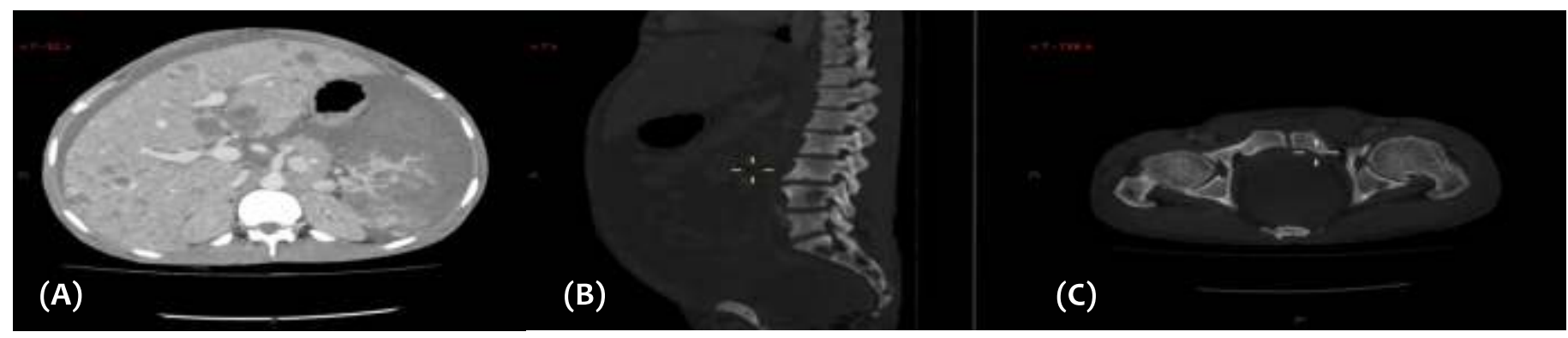

Figure 2: (A) Axial portovenous phase: Extrahepatic involvement with lesions replacing splenic parenchyma, becoming more Hypodense on portovenous phase- a pattern seen in hemangiomatosis. (B) Sagittal section bone window: Extrahepatic involvement with hemangiomas is $\mathrm{L} 4$ and $\mathrm{S} 1$ vertebral bodies. (C) Axial section bone window: there were changes of bilateral avascular necoriss in femoral heads, proposed cause in our case.

Received: November 16, 2020

Accepted: April 10, 2021

\section{REFRENCES}

1. Wanless IR. Vascular disorders. In: MacSween RN, Burt $A D$, Portmann BC, Ishak KG, Scheuer PJ, Anthony PP, eds. Pathology of the liver, 4th ed. Glasgow, UK: Churchill Living Stone 2002; 553-5.

2. Dai YN, Ren ZZ, Song WY, Huang HJ, Yang DH, Wang MS, et al. Peliosis hepatis: 2 case reports of a rare liver disorder and its differential diagnosis. Medicine (Baltimore) 2017; 96:e6471.

\section{doi:10.1097/MD.0000000000006471}

3. Elsing C, Placke J, Herrmann T. Alcohol binging causes peliosis hepatis during azathioprine therapy in Crohn's disease. World J Gastroenterol 2007; 13: 4646-8. doi: 10.3748/wig.v13.i34.4646

4. Iannaccone R, Federle MP, Brancatelli G, Matsui O, Fishman EK, Narra VR, et al. Peliosis hepatis: spectrum of imaging findings. AJR Am J Roentgenol 2006; 187: W43-52. doi: 10.2214/AJR.05.0167

5. Neri M, Bello S, Bonsignore A, Cantatore S, Riezzo I, Turillazzi E, et al. Anabolic androgenic steroids abuse and liver toxicity. Mini Rev Med Chem. 2011; 11:430-7. doi: $10.2174 / 138955711795445916$

6. Calabrese E, Hanauer SB. Assessment of non-cirrhotic portal hypertension associated with thiopurine therapy in inflammatory bowel disease. J Crohns Colitis 2011; 5:48-53.10.1016/j.crohns.2010.08.007
7. Gronlykke L, Tarp B, Dutoit SH, Wilkens R. Peliosis hepatis: a complicating finding in a case of biliary colic. BMJ Case Rep 2013; 2013:bcr2013200539. doi: $10.1136 /$ bcr-2013-200539

8. Testa G, Panaro F, Sankary H, Chejfec G, Mohanty S, Benedetti $E$, et al. Peliosis hepatis in a living related liver transplantation donor candidate. J Gastroenterol Hepatol 2006; 21:1075-7. doi: 10.1111/j.14401746.2006.03172.x

9. Chen JF, Chen WX, Zhang HY, Zhang WY. Peliosis and gummatous syphilis of the liver: a case report. World J Gastroenterol 2008;14:1961-3. doi:10.3748/wig.14.1961

10. Tsokos M, Erbersdobler A. Pathology of peliosis. Forensic Sci Int 2005; 149:25-33.

doi: 10.1016/j.forsciint.2004.05.010

11. Nesher G, Dollberg L, Zimran A, Hershko C. Hepatosplenic peliosis after danazol and glucocorticoids for ITP. N Engl J Med 1985; 312:242-3. doi:10.1056/nejm198501243120413

12. Vignaux $O$, Legmann $P$, de Pinieux $G$, Chaussade $S$, Spaulding C, Couturier D, et al. Hemorrhagic necrosis due to peliosis hepatis: imaging findings and pathological correlation. Eur Radiol 1999; 9:454-6. doi: $10.1007 /$ s003300050691

13. Wang SY, Ruggles S, Vade A, Newman BM, Borge MA. Hepatic rupture caused by peliosis hepatis. J Pediatr Surg 2001; 36:1456-9. doi: 10.1053/ipsu.2001.26397 